\title{
Response in Stock Size and Recruitment of Northern Shrimp (Pandalus borealis) to Changes in Predator Biomass and Distribution in West Greenland Waters
}

\author{
Kai Wieland ${ }^{1}$, Marie Storr-Paulsen ${ }^{2}$ and Kaj Sünksen \\ Greenland Institute for Natural Resources, PO Box 570, 3900 Nuuk, Greenland
}

Wieland, K., M. Storr-Paulsen, and K. Sünksen. 2007. Response in stock size and recruitment of northern shrimp (Pandalus borealis) to changes in predator biomass and distribution in West Greenland waters. J. Northw. Atl. Fish. Sci., 39: 21-33. doi:10.2960/J.v39.m579

\begin{abstract}
Potential relationships between stock size of Northern shrimp (Pandalus borealis) and its main predators, Atlantic cod (Gadus morhua) and Greenland halibut (Reinhardtius hippoglossoides), in West Greenland waters were examined. Changes in spatial overlap between the species were taken into account in the analysis of the impact of predator biomass on the survival of Northern shrimp recruits. Survey estimates of total stock size of Northern shrimp were negatively correlated with Atlantic cod biomass lagged by one and two years until the beginning of the 1990s. Thereafter, the Atlantic cod stock in West Greenland offshore waters collapsed, but no immediate response of Northern shrimp to the released predation pressure was observed. Recruitment and subsequently stock biomass of Northern shrimp increased first about 10 years later following a moderate increase in the temperature conditions, which had likely enhanced plankton productivity. After a record high level in 2000, survival of juvenile Northern shrimp, i.e. the number of recruits at age 2 per unit of spawning stock biomass, decreased drastically. Statistical analysis suggests that increased predation by Greenland halibut have overruled the positive effect of favourable temperature conditions in the most recent years. In contrast, the impact of Atlantic cod on Northern shrimp was insignificant in the recent years due to low Atlantic cod biomass and a very limited spatial overlap between the two species.
\end{abstract}

Key words: Atlantic cod, Greenland halibut, shrimp, spatial distribution, top-down control

\section{Introduction}

Northern shrimp (Pandalus borealis) is a protandric hermaphrodite with a circumpolar distribution in the northern hemisphere, changing to the female stage after 4-7 years as a male in West Greenland waters (Shumway et al., 1985; Bergström, 2000). Northern shrimp feeds on phytoplankton, detritus and small zooplankton and serves in turn as an important prey for many fish species. In relation to its trophic level, responses to changes in both bottom-up and top-down processes have been found (Fuentes-Yaco et al., 2007; Lilly et al. 2000).

Close linkages between populations of Atlantic cod and Northern shrimp have been described for various parts of the North Atlantic (Worm and Myers, 2003). Short-term responses, i.e. with time lags of less than 2 or 3 years, of stock size of Northern shrimp to changes in Atlantic cod biomass have been documented in the Barents Sea and Icelandic waters (Stefánsson et al., 1998; Berenboim et al., 2000). Furthermore, it has been concluded that the reduction in predation by At- lantic cod have contributed to the increase in Northern shrimp biomass of Newfoundland and Labrador (Lilly et al., 2000), despite some uncertainty concerning the role of other predators or environmental factors relevant for bottom-up processes in the food web (Parsons, 2005a, b; Frank et al., 2006). Greenland halibut have been identified as another important predators of Northern shrimp in the North Atlantic (Pedersen and Riget, 1993; Orr and Bowering, 1997; Grunwald, MS 1998; Parsons, 2005a), but estimated consumption of Northern shrimp by Greenland halibut were about 10 fold lower than those computed for Atlantic cod in West Greenland waters (Grunwald, 1998).

Considering the predator-prey relationship between Atlantic cod and Northern shrimp found in various parts of the North Atlantic, Hvingel and Kingsley (2006) developed a production model, which includes explicit cod biomass and predation terms, for the Northern shrimp stock at West Greenland, and this model has been adopted by NAFO and used since 2002 to assess and manage the resource (NAFO, MS 2006).

Present Addresses: ${ }^{1}$ Technical University of Denmark / Danish Institute for Fisheries Research, North Sea Center, 9850 Hirtshals, Denmark, ${ }^{2}$ Technical University of Denmark / Danish Institute for Fisheries Research, Charlottenlund Castle, 2920 Charlottenlund, Denmark 
After some violent fluctuations during the 1970s and 1980s, Atlantic cod disappeared from West Greenland waters in the beginning of the 1990s (Buch et al., 1994). An indication for some recovery of Atlantic cod was first found after 2003 when survey catch rates increased slightly at Southwest Greenland (ICES, MS 2006). Indices of Northern shrimp stock size fluctuated during the late 1970 s and the early 1980 s, were relatively stable at a low level during the 1990s and increased to record high values thereafter (Kingsley, MS 2006; Wieland and Bergström, MS 2006). The increase in Northern shrimp biomass was preceded by a couple of years with increasing recruitment and it has been suggested that an increase in sea temperature in the mid 1990s has been beneficial for survival and growth of juvenile Northern shrimp (Wieland, 2005a). While total biomass remained high in the most recent years Northern shrimp began to disappear from the southern areas, in which temperature probably have exceeded the optimal level for this species $\left(3-6^{\circ} \mathrm{C}\right.$ according to Shumway et al., 1985), and recruitment declined drastically in the main distributional area without any further change in temperature (Wieland and Bergström, MS 2006). The latter coincided with a substantial increase of juvenile Greenland halibut biomass (Sünksen et al., MS 2006), and some indication was found that the increase in juvenile Greenland halibut biomass had a negative effect on the recruitment of Northern shrimp (Wieland, MS 2004).

In the present study, possible relationships between the stock dynamic of Northern shrimp and its two main predators in West Greenland waters, Atlantic cod and Greenland halibut, were explored. This was complemented by an examination of a potential impact of the two predators and on the reproductive success of Northern shrimp, which explicitly considered changes in spatial overlap between Northern shrimp and Atlantic cod and between Northern shrimp and juvenile Greenland halibut.

\section{Methods}

\section{Survey Information}

Data from two different stratified-random bottom trawl surveys were used in this study according to their efficiency for the two target species. These were a German groundfish survey conducted by the Institute of Sea Fisheries Hamburg (ISH) annually in the autumn since 1982 and a Greenland survey for shrimp and fish carried out by the Greenland Institute of Natural Resources (GNIR) annually in the summer since 1988 .

The ISH survey covers the shelf area outside the three nautical mile limit and the continental slope down to a depth of $400 \mathrm{~m}$ between $67^{\circ} 00^{\prime} \mathrm{N}$ and $59^{\circ} 30^{\prime} \mathrm{N}$ (Fig. 1) off West Greenland. However, the area between $64^{\circ} 15^{\prime} \mathrm{N}$ and $67^{\circ} 00^{\prime} \mathrm{N}$ has not been sampled every year (1995, 2001-2003 and 2005 missing) and in 1995 only 3 stations were taken between $62^{\circ} 30^{\prime} \mathrm{N}$ and $64^{\circ} 15^{\prime} \mathrm{N}$. The fishing gear used has a vertical opening of about $4 \mathrm{~m}$ and the towing speed is 4 knots. The survey has primarily been designed for Atlantic cod. It neither allows representative estimates of Northern shrimp density nor adequately covers the distributional range of Greenland halibut (Fig. 2).

The GNIR survey for fish and shrimp covers the West Greenland shelf between 72 $30^{\prime} \mathrm{N}$ and 59 $30^{\prime} \mathrm{N}$ down to the $600 \mathrm{~m}$ depth (Fig. 1). The survey area has been expanded through time and full coverage was first attained in 1993. The fishing gear has a vertical opening of about $14 \mathrm{~m}$ and the towing speed is 2.5 knots. The trawl was changed in 2005 and due to the change in the ground-rope from a bobbin chain to a rubber disc/bobbin rock-hopper gear, higher catches especially for small groundfish were found (Sünksen et al., MS 2006). The primary objective of the survey is to provide an estimate of the fishable biomass of Northern shrimp, and the survey is considered to be less efficient for Atlantic cod, in particular for the years prior to 2005 .

\section{Time Series of Stock Size}

No analytical assessment for Atlantic cod off West Greenland exists for the recent decades as the directed offshore fishery stopped in the beginning of 1990s. Biomass estimates (for age 3 and older) were available from a traditional Virtual Population Analysis (VPA) for the periods 1924 to 1989 (Buch et al., 1994) and the German groundfish survey provides area-aggregated biomass estimates (age 0 and older) since 1982. The average ratio of survey to VPA estimates for the overlapping period were close to $1($ mean $=1.003$, s.e. $=0.22$; Wieland and Storr-Paulsen, MS 2004), which allows to combine the VPA data (until 1989) and the survey estimates (since 1990) into one time series of stock size of Atlantic cod.

For Northern shrimp, two independent series of stock size indices were used. The two series were a standardized catch per unit effort (CPUE) index from the commercial fishery (Kingsley, MS 2006) and the total biomass estimates from the Greenland survey for shrimp and fish (Wieland and Bergström, MS 2006). Due to the change of the survey trawl in 2005, the historical survey catches have been converted using length-dependent conversion factors (Wieland, MS 2005b). However, this conversion did not account for the larger swept area of the new trawl. The average ratio of the swept areas of the two trawls $($ mean $=0.8708$, s.e. $=0.0075)$ from a trawl 


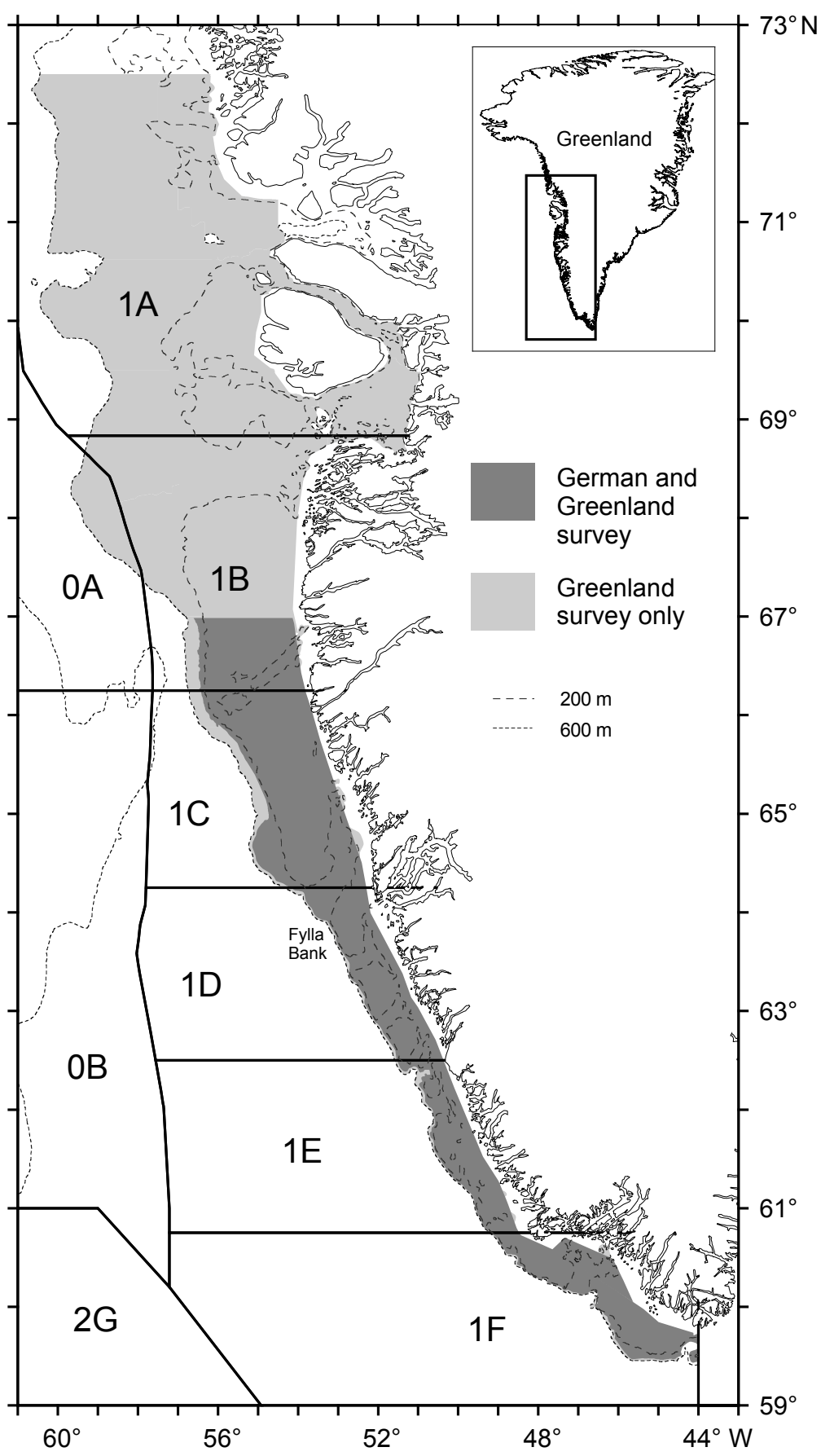

Fig. 1. NAFO statistical divisions and area coverage of the German groundfish survey and the Greenland survey for shrimp and fish off West Greenland.

calibration experiment (Rosing and Wieland, MS 2005) were applied here to adjust the biomass estimates for the period 1988 to 2004 to the new standard trawl used in 2005.

For Greenland halibut, a biomass index derived from the Greenland bottom trawl survey for shrimp and fish was used. This index, however, comprises mainly the juvenile portion of the stock as individuals larger than $60 \mathrm{~cm}$ are predominantly found at depths of more than $600 \mathrm{~m}$, which are not covered by this survey (Jørgensen, 1997). The results from the trawl calibration experiment for Greenland halibut are still being analyzed, and hence the 2005 estimate was converted preliminarily to the old 

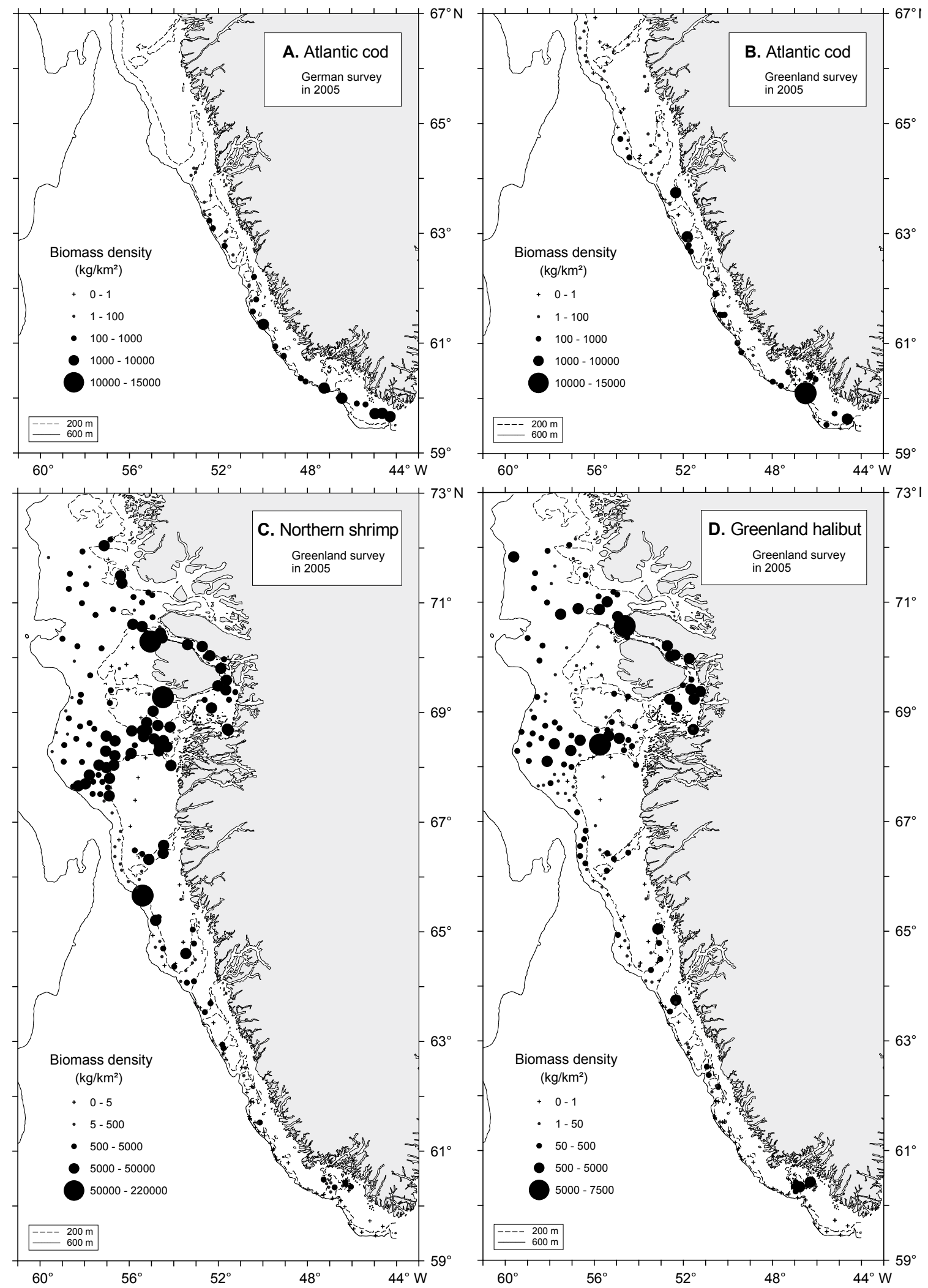

Fig. 2. Distribution of (A) Atlantic cod from the German survey, and (B) Atlantic cod, (C) Northern shrimp and (D) Greenland halibut from the Greenland survey, in 2005. 
trawl standard using a size-dependent conversion of the catches (Sünksen et al., MS 2006) and an adjustment for the smaller average swept area fished with the old trawl $($ mean $=1.1516$, s.e. $=0.0097)$.

\section{Temperature Data}

Surface layer $(0-40 \mathrm{~m})$ temperatures measured at a standard oceanographic station on Fylla Bank were taken from Ribergaard (MS 2006). For both, the German groundfish survey and the Greenland survey for shrimp and fish, area-weighted mean bottom water temperatures were calculated from the temperatures measured on the trawl tracks and the area of the corresponding survey strata.

\section{Comparison of spatial distributions}

Geo-referenced survey data (biomass density per tow) for Atlantic cod from the German groundfish survey and for Northern shrimp and Greenland halibut from the Greenland survey for shrimp and fish were used to examine the spatial overlap between the two species. A geostatistical tool, the global index of collocation (GIC) developed by Bez and Rivoirard (2000) for pelagic species and used by Hendrickson and Vázquez (2005) for demersal fish, was applied for this purpose. The GIC is based on computing both the centre of gravity $(C G)$ and the inertia $(I)$ of a population. The coordinates of the centre of gravity are computed as:

$$
C G=\left\{\begin{array}{l}
\frac{\sum_{i} u_{i} z_{i}}{\sum_{i} z_{i}} \\
\frac{\sum_{i} v_{i} z_{i}}{\sum_{i} z_{i}}
\end{array}\right.
$$

where $u_{i}$ is the longitude, $v_{i}$ is the latitude and $z_{i}$ is the observed density at each sampling location $i$. The inertia is a measure of the horizontal dispersion of the population and is calculated as the mean squared distance between an individual sample and the centre of gravity in surface area units:

$$
I=\frac{\sum_{i}\left(x_{i}-C G\right)^{2} z_{i}}{\sum_{i} z_{i}}
$$

where $x_{i}$ is the position of an individual sample. An annual GIC value is then computed as:

$$
G I C=1-\frac{\Delta C G^{2}}{\Delta C G^{2}+I_{1}+I_{2}}
$$

where $\Delta C G^{2}$ is the distance between the centres of gravity of the two populations and $I_{1}$ and $I_{2}$ represents the respective inertias.

The GIC is a spatial statistic ranging from 0 , where each population is concentrated on a single but different location, to 1 , when the two centres of gravity are coincident. It is not influenced by the occurrence of zero catches and does not assume a specific geometrical shape of the species distribution, but requires that the distributional range of the two species is sampled with a comparable level of spatial integration (Bez and Rivoirard, 2000). Ellipses of the inertia, which would represent the main directions of the dispersion but not the spatial distribution in itself as suggested in Hendrickson and Vázquez (2005), were not estimated in the present study.

\section{Female Spawning Stock Biomass and Recruitment of Northern Shrimp}

Horsted (MS 1978) summarized information on the spawning period of Northern shrimp at West Greenland noting that not all females became ovigerous during winter of the same year and that the proportion of spawning females varied between 20 and $90 \%$ in different areas and years, but no relationship with temperature could be established from his observations. Skúladóttir et al. (MS 1991) reported that Northern shrimp does not spawn every year in Iceland offshore waters whereas the proportion of egg bearing females during winter was about $95 \%$ in inshore areas at higher temperatures. A second order polynomial regression was fitted to these data and was used to calculate the proportion of mature females in West Greenland waters for the years 1990 to 2005 (Fig. 3) based on the bottom temperatures observed there (Fig. 4). The original survey estimates of female biomass were then multiplied with the temperature-specific maturity proportion in order to obtain a time series of the female spawning stock. Recruitment indices for age 2 were obtained by modal analysis of regional length frequencies for juveniles and males using the MIX 3.1A software released in 1993 (MacDonald and Pitcher, 1979; MacDonald and Green, 1988). The regions for pooling the original length frequencies were defined considering latitudinal gradients in bottom temperature (Wieland, MS 2004). No smoothing of the length frequency histograms was applied prior to the analysis. Initial estimates of the modes and the number of age groups to be considered were obtained by visual inspec- 

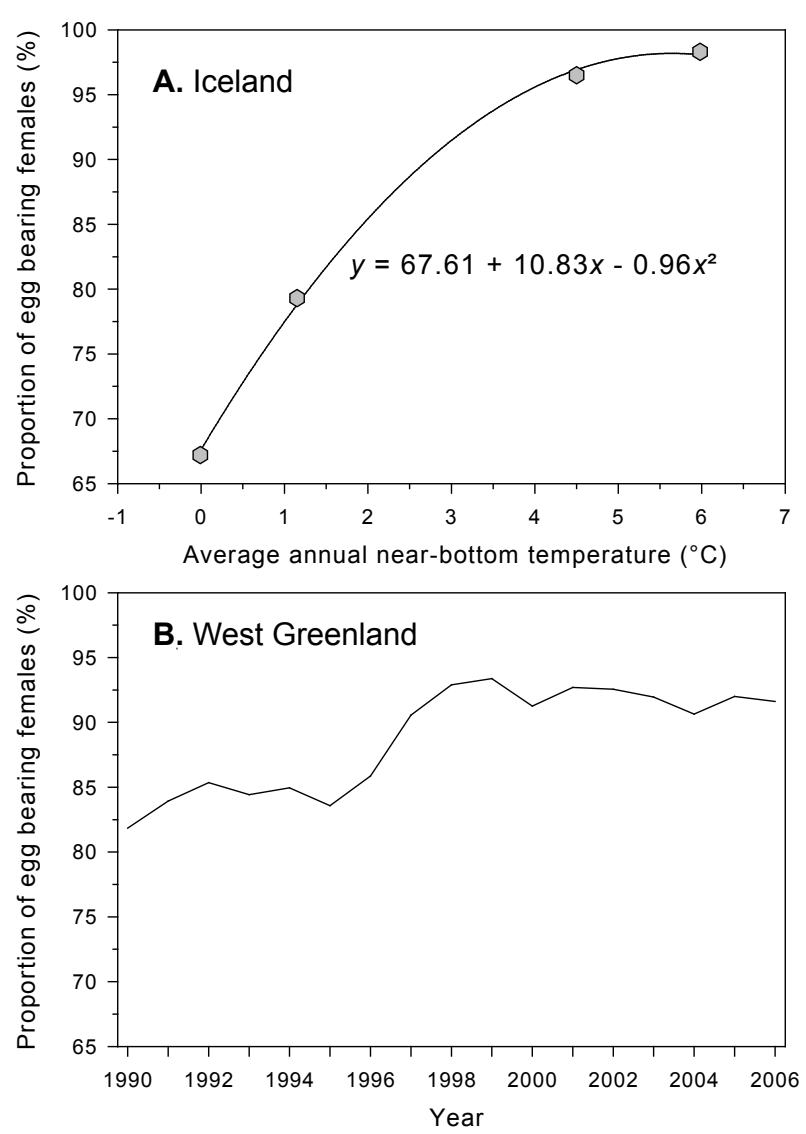

Fig. 3. (A) Proportion of egg bearing females of Northern shrimp during winter (December) in relation to bottom temperature at Iceland (based on Skúladóttir et al., MS 1991), and (B) estimated proportion of spawning females of Northern shrimp at West Greenland based on the regression obtained from the Icelandic data and the observed bottom temperatures in the Greenland survey for shrimp and fish (Fig. 4).

tion of the length frequencies. A constant coefficient of variation for length at age was used in the MIX analysis during a first run. However, because the first age group was not well represented in many of the samples, since a proportion of the larger males had already changed sex and differences in growth between cohorts were likely, varying coefficients of variation were finally used. Both, female spawning stock biomass and recruitment from the years prior to 2005 were adjusted to the new trawl standard as described above.

\section{Predator Effects on Recruitment}

The number of recruits per unit of parental biomass that produced the recruits is usually interpreted as an index of survival and can be used as a measure the

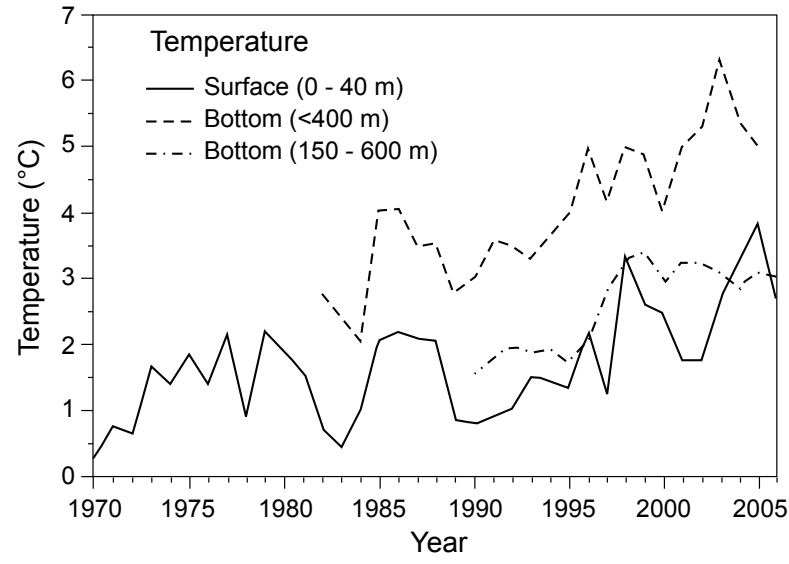

Fig. 4. Time series of sea temperature in the surface layer (0-40 m depth, Fylla Bank) and in the bottom water at $<400 \mathrm{~m}$ depth from $59^{\circ} 30^{\prime}-67^{\circ} 00^{\prime} \mathrm{N}$ and at $150-600$ $\mathrm{m}$ depth from $59^{\circ} 30^{\prime}-72^{\circ} 30^{\prime} \mathrm{N}$.

reproductive success. Here, a lag of three years between female spawning stock biomass and age 2 recruits was used taking into account that the females found in a summer survey produce offspring that emerge as larvae first in the following spring and are caught as age 2 in the survey three years later.

In order to examine a potential impact of changes in Atlantic cod and Greenland halibut stock size and distribution on the survival index of Northern shrimp recruits effective biomasses of Atlantic cod and Greenland halibut were calculated by multiplying the survey indices of total biomass with the corresponding indices of collocation in the single years.

\section{Correlation analysis}

A non-parametric method, Spearman rank correlation analysis, was used whenever a significant $(P=0.05)$ deviation from normality was detected. This was the case for the entire time series of Atlantic cod biomass as well as the two indices of Northern shrimp stock size (commercial CPUE and survey biomass), also after logtransformation. Subsets of these data series, i.e. the last nine years, and the biomass index for Greenland halibut did not indicate significant deviation from normality, which allowed the use of the parametric methods of linear regression and Pearson product moment correlation analysis.

The data series showed significant $(P=0.05)$ autocorrelation with lags of one and two years. To account for the autocorrelation in the data the degrees of freedom 
in the correlation tests were adjusted according to Pyper and Peterman (1998):

$$
\frac{1}{N^{*}}=\frac{1}{N}+\frac{2}{N} \sum_{j} r_{x x}(j) r_{y y}(j)
$$

where $N^{*}$ is the effective number of degrees of freedom on the time series $X$ and $Y, N$ is the sample size and $r_{X X}(j)$ and $r_{Y Y}(j)$ are the autocorrelations of $X$ and $Y$ at lag $j$. The latter were estimated as:

$$
r_{x x}(j)=\frac{\sum_{t=1}^{N-j}\left(X_{t}-\bar{X}\right)\left(X_{t+1}-\bar{X}\right)}{\sum_{t=1}^{N}\left(X_{t}-\bar{X}\right)^{2}}
$$

where $\bar{X}$ is the overall mean. Following the recommendation by Pyper and Peterman (1998) a maximum of N/4 lags were considered in the calculation of the effective number of degrees of freedom.

\section{Results}

\section{Temperature Conditions}

Sea temperature in the surface layer was relative high $\left(\approx 2^{\circ} \mathrm{C}\right)$ during most years in the 1970 s and in the second half of the 1980s (Fig. 4). These warm periods were interrupted by a few years with low temperatures $\left(<0.5^{\circ} \mathrm{C}\right)$. Since the beginning of the $1990 \mathrm{~s}$, the surface temperature showed an increasing trend towards a record high value recorded in $2005\left(3.8^{\circ} \mathrm{C}\right)$. Similarly, the area-weighted mean bottom temperatures from the German groundfish survey revealed a warm period in the late $1980 \mathrm{~s}\left(\approx 4^{\circ} \mathrm{C}\right)$ and increased during the 1990 s from less than $3^{\circ} \mathrm{C}$ to more than $5^{\circ} \mathrm{C}$ after 2000 . The areaweighted mean bottom temperatures from the Greenland survey for shrimp and fish were lower than those from the German groundfish survey as the latter is restricted to the area south from $67^{\circ} \mathrm{N}$. Here, the bottom temperature showed first in the mid 1990s an increase from less than $2^{\circ} \mathrm{C}$ to more than $3^{\circ} \mathrm{C}$, which suggests a slightly delayed warming in the northern area.

\section{Trends in Stock Size and Correlations}

The biomass of Atlantic cod declined drastically until the early 1970s (Fig. 5). Some recovery was observed during relative warm periods in the late 1970s and early 1980 s as well as in the second half of the 1980s. Thereafter, Atlantic cod has almost been absent from West Greenland offshore waters until a slight rise in stock biomass began in 2001. The actual biomass of Atlantic cod, however, amounts to less than $10 \%$ of the level seen in the late $1980 \mathrm{~s}$.
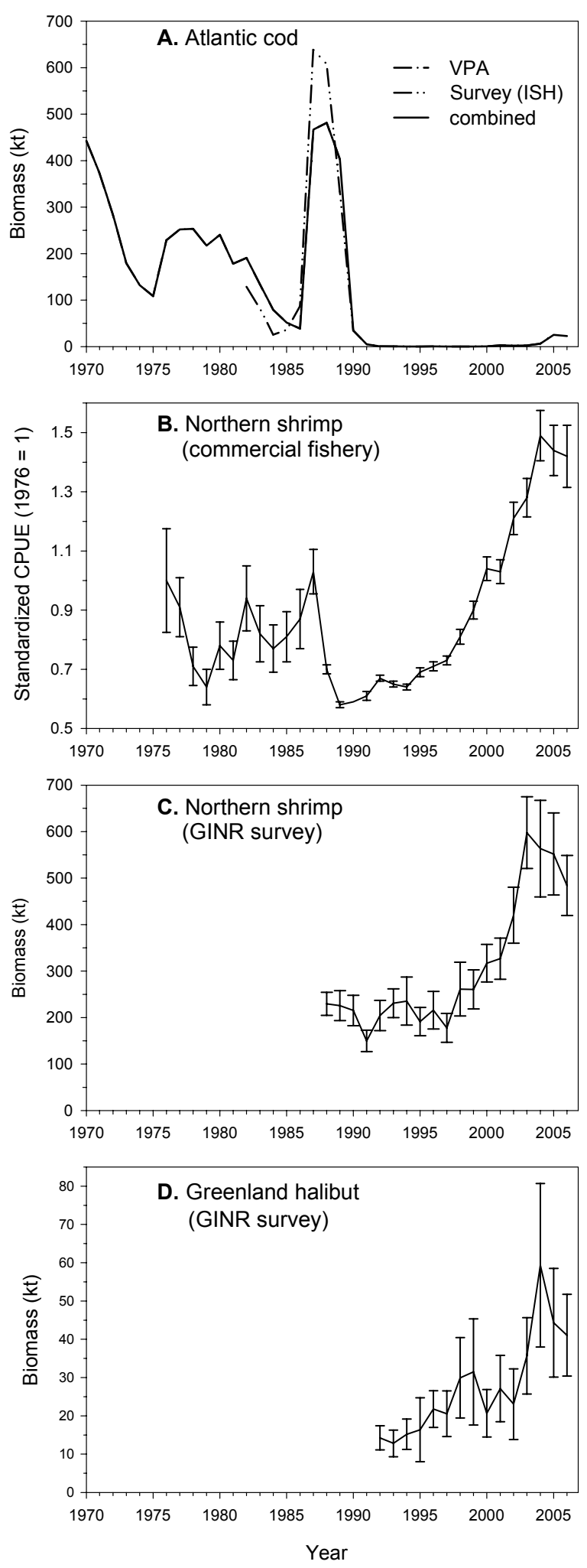

Fig. 5. (A) Time series of Atlantic cod biomass (VPA and German (ISH) survey), (B) modelled CPUE from the commercial fishery for Northern shrimp (error bars refer 25 and $75 \%$ quartile range), (C) biomass indices (Greenland (GINR) survey) for Northern shrimp (error bars refer to $+/-1$ standard error), and (D) Greenland halibut (error bars refer to $95 \%$ confidence interval). 
The standardized CPUE from the commercial fishery for Northern shrimp was variable, but on average moderately high during the last 1970s and the first half of the 1980s (Fig. 5). It then fell to uniform lower levels until the end of the 1990s, since when it has continuously increased to its present record high level. The survey estimates of total biomass of Northern shrimp off West Greenland showed little variation over the initial 10-year period, but after a comparatively low level in the end of the 1990s the biomass increased by a factor of three within five years and remained thereafter at this record high level (Fig. 5).

The biomass index for Greenland halibut increased slowly but more or less continuously during the 1990s (Fig. 5). Thereafter, the biomass estimates for juvenile Greenland halibut doubled within three years and remained on a relative high level in the last years.

Neither the standardized CPUE from the commercial fishery for Northern shrimp (1976-2006) nor the survey estimates of Northern shrimp biomass (1988-2006) showed significant correlation with the biomass of Atlantic cod over the entire range of the time series whatever time lag has been applied (Table 1). However, highly significant $(P<0.01)$ negative correlations between the CPUE for Northern shrimp and Atlantic cod biomass with time lags of one or two years were found when excluding the period after 1991 or 1992, respectively (Fig. 6), which indicates that the previous link between Atlantic cod and Northern shrimp stock dynamics broke down in the early 1990s. Any significant correlations were obtained for these periods applying no lag or time lags of 3 and 4 years. Between the survey estimates of total stock biomass of Northern shrimp and Greenland halibut no significant negative correlations were detected when time lags of $0-4$ years were applied.

\section{Geographical Distribution and Spatial Overlap}

The mean latitude weighted by the biomass densities at the sampling locations were almost uniform around $62^{\circ} \mathrm{N}$ for Atlantic cod in the years before 1987 (Fig. 7). Thereafter, mean latitude began to vary considerably until a southward shift in the distribution is indicated in particular since 2003. For Atlantic cod, the decrease in mean latitude was also accompanied with a decline in mean latitude, and resulted in 2005 in the most southeastern located centre of the distribution in the time series. This distribution pattern was found in both, the German and the Greenland survey (Fig. 2). The centre of gravity of the biomass distribution of Northern shrimp was in all years several degrees latitude further north located than that of Atlantic cod, but showed a decreasing trend during the 1990s (Fig. 7). During in the past four years the distribution of Northern shrimp returned to its initial pattern and in 2005 the mean latitude reached approximately $69^{\circ} \mathrm{N}$, which is the highest value in the time series at all (Fig. 7). The mean latitude of the distribution of Greenland halibut was relative stable throughout all the years ranging from $68-69^{\circ} \mathrm{N}$ (Fig. 7). The distributions of both, Northern shrimp and Greenland halibut showed low variation in mean longitude ranging from $52-55^{\circ} \mathrm{W}$ (Fig. 7).

The GIC between Northern shrimp and Atlantic cod fluctuated between 0.28 and 0.64 in most of the years but declined from 0.38 in 2003 to 0.09 in 2005 (Fig. 7). A similar trend was found using the data from the Greenland survey for both species, and the distribution pattern of Atlantic cod observed in the Greenland survey in 2005 (Fig. 2) would give a GIC value for the overlap with Northern shrimp of 0.08 . For 2006, both surveys indicate a small increase in the spatial overlap of the two species with $G I C$ values of about 0.2 .

TABLE 1. Correlation between standardized CPUE of Northern shrimp from the commercial fishery and Atlantic cod biomass $(N=31)$ and between Northern shrimp survey biomass and cod biomass $(N=19)$ for different time lags $\left(r_{S}\right.$ : Spearman rank correlation coefficient, $N^{*}$ : effective number of degrees of freedom, $P^{*}$ : associated probability).

\begin{tabular}{ccccccc}
\hline \hline \multirow{2}{*}{$\begin{array}{c}\text { Lag } \\
\text { (yrs })\end{array}$} & \multicolumn{2}{c}{ Shrimp CPUE vs Cod biomass } & \multicolumn{3}{c}{ Shrimp biomass vs Cod biomass } \\
\cline { 2 - 7 } & $r_{s}$ & $N^{*}$ & $P^{*}$ & $r_{s}$ & $N^{*}$ & $P^{*}$ \\
\hline 0 & 0.003 & 12 & $>0.05$ & 0.200 & 8 & $>0.05$ \\
1 & -0.270 & 12 & $>0.05$ & -0.014 & 8 & $>0.05$ \\
2 & -0.394 & 12 & $>0.05$ & -0.121 & 8 & $>0.05$ \\
3 & -0.411 & 12 & $>0.05$ & -0.367 & 8 & $>0.05$ \\
4 & -0.375 & 12 & $>0.05$ & -0.549 & 8 & $>0.05$ \\
\hline
\end{tabular}



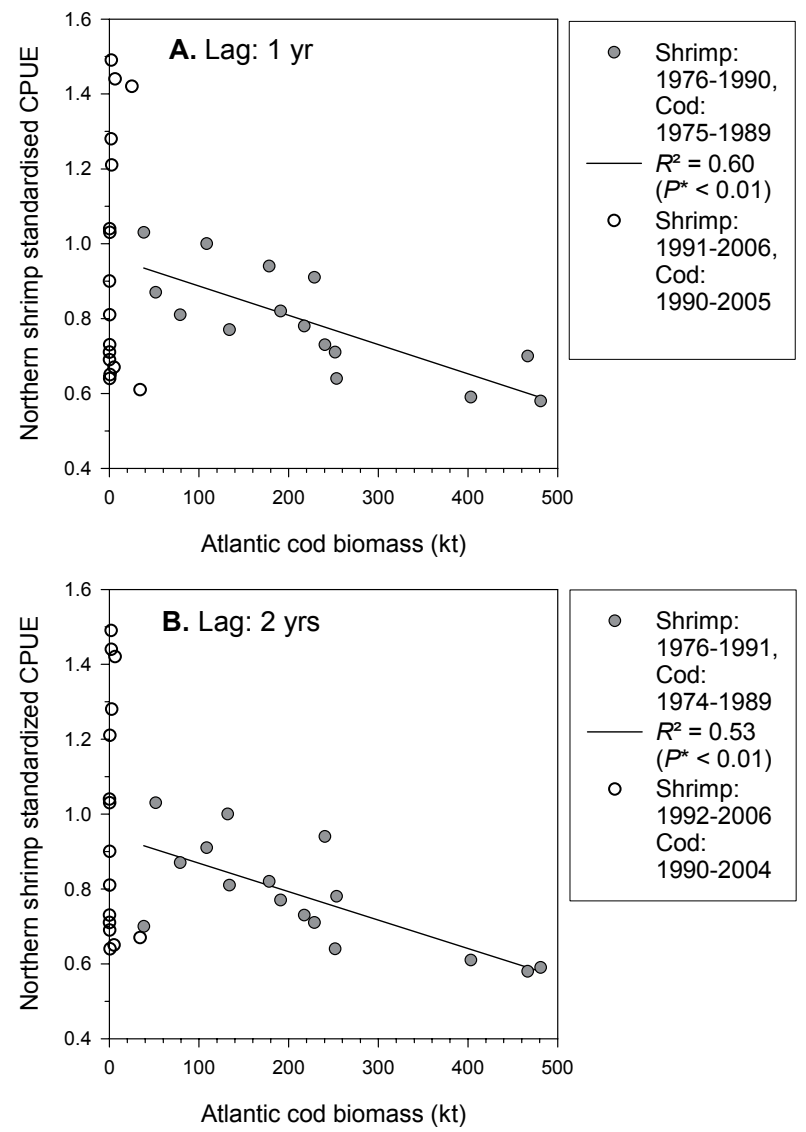

Fig. 6. Comparison of Northern shrimp CPUE from the commercial fishery with Atlantic cod biomass for two different periods and time lags of (A) one and (B) two years $\left(P^{*}\right.$ : associated probability corrected for autocorrelation with $N^{*}=10$ degrees of freedom).

The index of collocation between the Northern shrimp and Greenland halibut was in general high than that for Northern shrimp and Atlantic cod increasing from 0.68 in 1997 and 0.99 in 2005 (Fig. 7), which was mainly due to the northward shift in the distribution of Northern shrimp in this period.

\section{Survival of Northern Shrimp Recruits and Effective Biomass of Predators}

The female spawning stock biomass of Northern shrimp was fairly stable during the 1990 s, increased to the highest value in the time series in 2003 and remained at a level considerably higher than the long-term average in the past three years (Fig. 8). The increase in female spawning stock biomass was preceded by a couple of years with high recruitment in the late 1990s, but thereafter recruitment decreased almost continuously (Fig. 8). Low recruitment despite relative high female spawn-
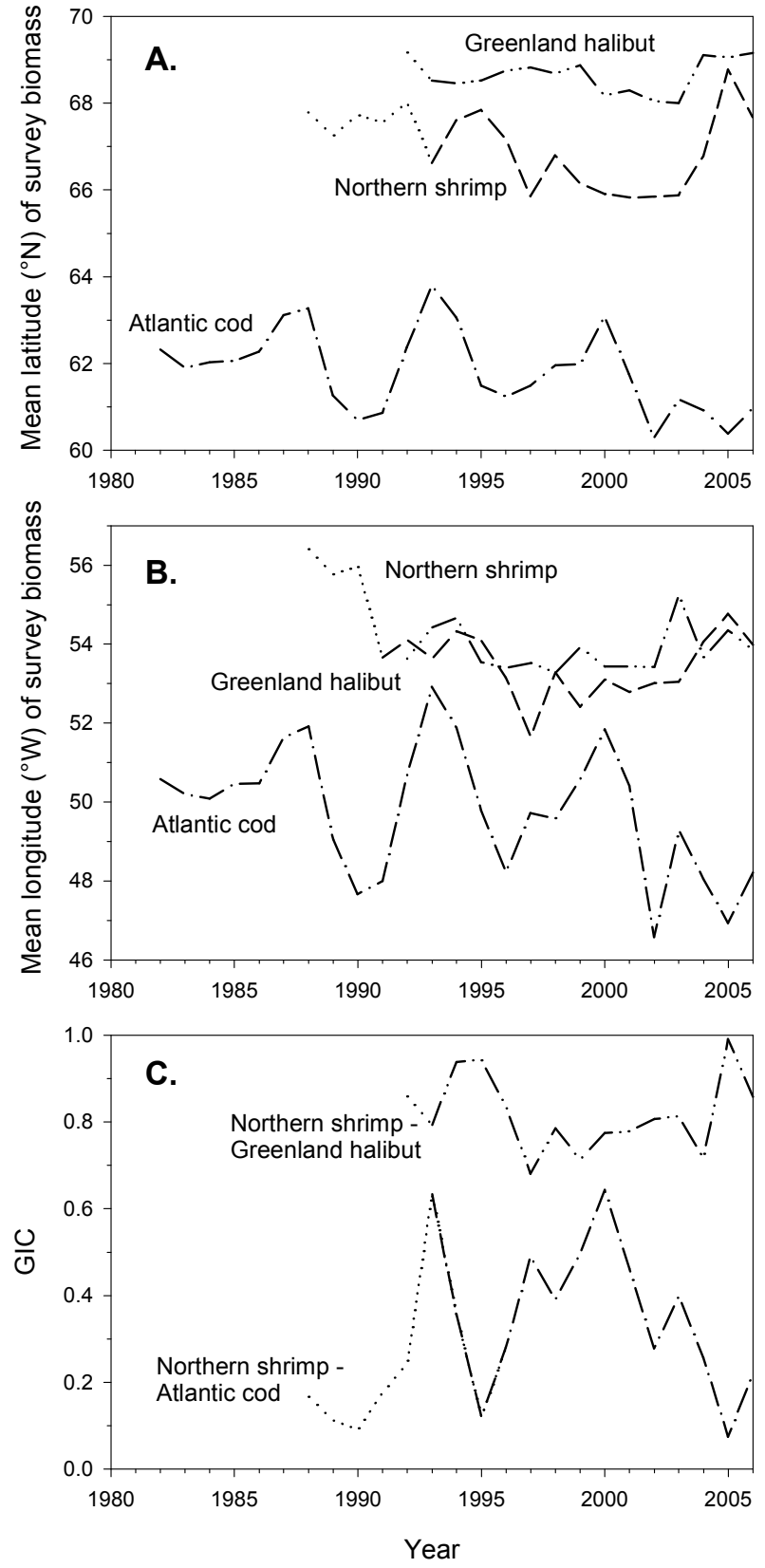

Fig. 7. Time series of survey biomass for Atlantic cod (German groundfish survey), Greenland halibut and Northern shrimp (Greenland survey for shrimp and fish), for (A) mean latitude and (B) mean longitude, and (C) the global index of collocation (GIC) for Northern shrimp and the two predatory species (dotted lines indicate years with incomplete survey coverage).

ing stock biomass means a lower survival of juvenile Northern shrimp before entering the fishery, which is reflected by the drastic decline of the recruit per unit of spawner biomass since 2001 (Fig. 8). 

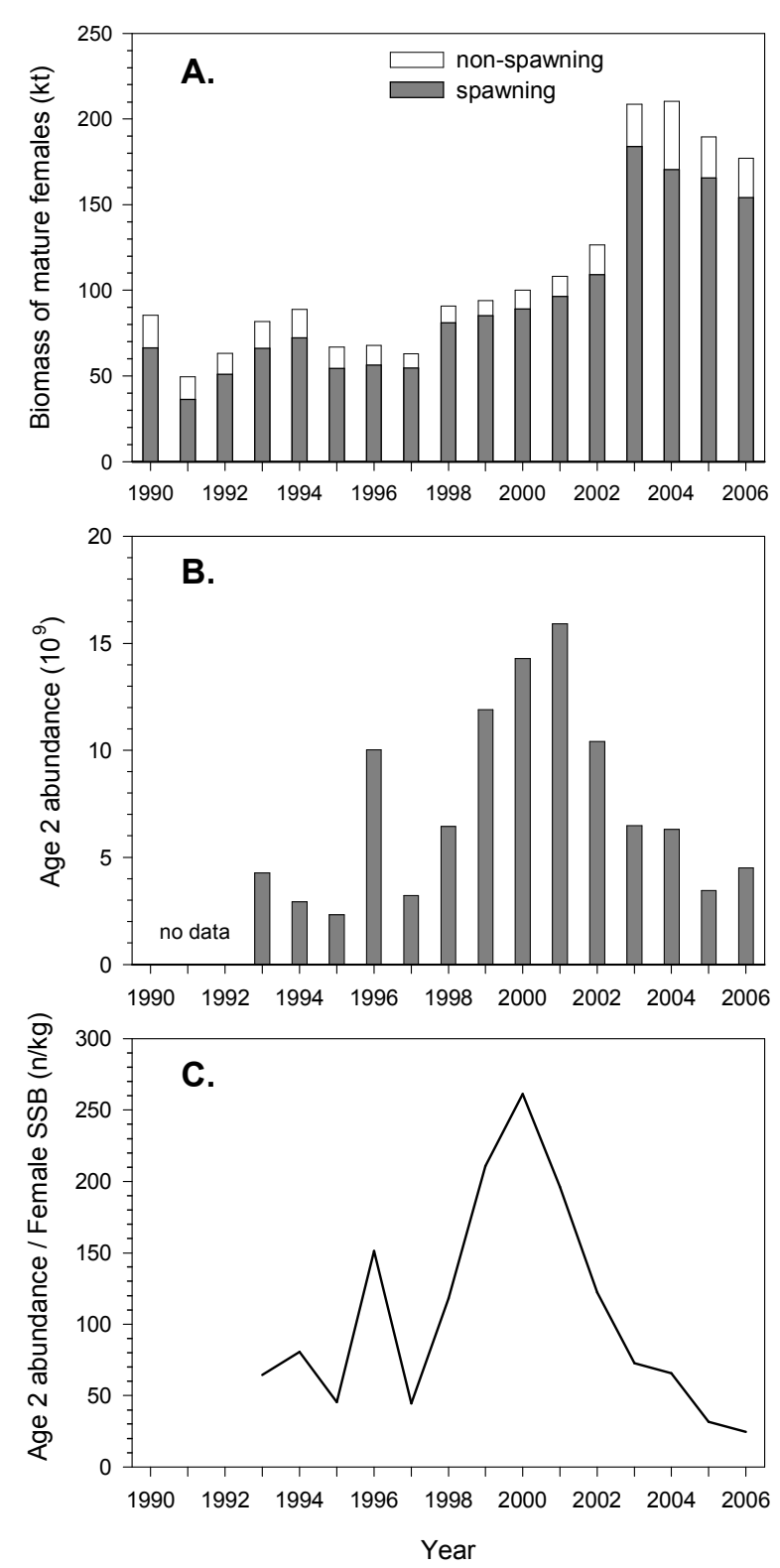

Fig. 8. (A) Biomass of mature non-spawning and spawning females, (B) recruitment at age 2 and $(\mathbf{C})$ recruits per unit of female spawning stock biomass, of Northern shrimp.

No relationship between Northern shrimp recruit survival and the indices of total survey biomass of Atlantic cod and Greenland halibut was found. The same result was obtained when using the corresponding indices of effective biomass for the entire available period of observations, i.e. 1993-2006, as well as for Atlantic cod in the last nine years when the Northern shrimp recruit survival index showed the most pronounced changes (Fig. 9). In contrast, a significant $(P<0.05)$ negative correlation between Northern shrimp recruit survival and
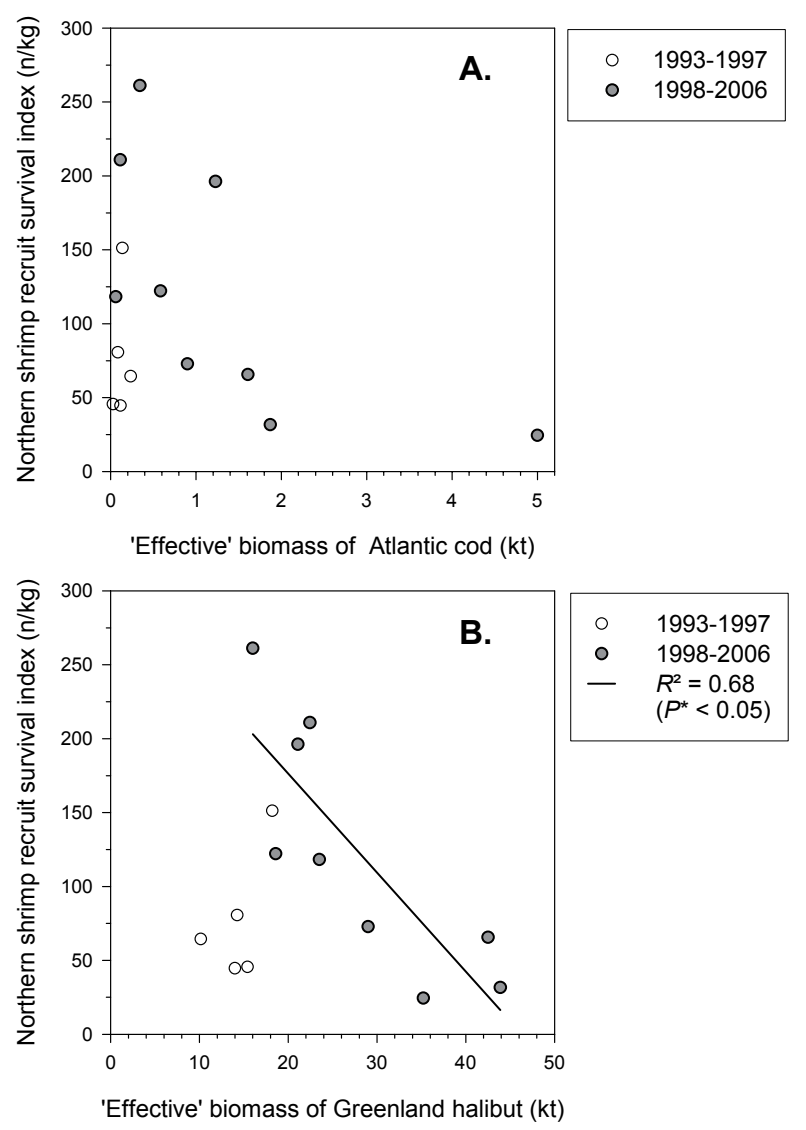

Fig. 9. Comparison of Northern shrimp recruit survival index with biomass indices for (A) Atlantic cod, (B) and Greenland halibut, adjusted for spatial overlap between Northern shrimp and the two predators $\left(P^{*}\right.$ : associated probability corrected for autocorrelation with $N^{*}=5$ degrees of freedom).

the effective biomass of Greenland halibut emerged in the years 1998 to 2006 (Fig. 9).

\section{Discussion}

In this study, potential relationships between stock sizes of Atlantic cod, juvenile Greenland halibut and Northern shrimp have been examined using correlation analysis. If data series are strongly autocorrelated the assumption of serial independence is violated and there is a larger chance of concluding that a correlation is statistically significant when in fact no correlation is present (Pyper and Peterman, 1998). Most of data series used in the present analysis contained positive autocorrelation for time lags of one or two years. No attempts were made to remove the autocorrelation, which would increase the probability of failing to detect a relationship between long-term, slowly changing environmental processes when it is in fact there. Instead, the degrees of freedom 
were adjusted for the determination of the critical significance levels according to the approach suggested by Pyper and Peterman (1998).

The German groundfish survey covered the distributional range of Atlantic cod in West Greenland offshore waters fairly well, despite of its the restriction to the area south of $67^{\circ} 00^{\prime} \mathrm{N}$ in general and south of $64^{\circ} 15^{\prime} \mathrm{N}$ in some years (ICES, MS 2006). The comparison with the Greenland survey for fish and shrimp, which has a much wider geographical extension towards the north, indicates further that the main part of the Atlantic cod distribution is sampled with a comparable intensity in both surveys. The GIC for the spatial overlap between Atlantic cod and Northern shrimp derived from the two surveys were almost identical with those calculated from the Greenland survey only since 2005 , i.e. after the change towards a more sufficient groundfish trawl in the latter one. It is therefore concluded that basic assumptions for the application of the GIC were met and that the findings concerning the recent changes in the geographical overlap of the two species are not seriously biased.

Responses of stock size of Northern shrimp to changes in Atlantic cod biomass with lags of one or two years have been documented in the Barents Sea and Icelandic waters (Stefánsson et al., 1998; Berenboim et al., 2000). These time lags suggest that Atlantic cod feeds in particular on shrimp stages smaller than those which usually contribute the major proportion of survey estimates of total biomass or commercial catches as reported by Lilly et al. (1998) for the Labrador and eastern Newfoundland shelf area.

A significant impact of Atlantic cod stock size on the biomass of Northern shrimp was detected until the beginning of the 1990s, but thereafter the stock dynamics of the two species were apparently no longer linked. The Northern shrimp stock showed no immediate response to the drastic decline of the Atlantic cod biomass and the southward shift in its distribution. The long delay between the pronounced surge in Northern shrimp biomass and the disappearance of Atlantic cod may suggest that factors other than a release from predation pressure by Atlantic cod have become more important in the last decade. However, the impact of Atlantic cod may rapidly become important again if the biomass increases and its distribution reverse towards a larger spatial overlap with Northern shrimp.

Both, the stock size of Northern shrimp and Greenland halibut have increased since the late 1990s. It appears that both species might have benefited from higher zooplankton productivity as this usually coincides with an increase in temperature (Pedersen and Smidt, 2000; Pedersen and Rice, 2002), which preceded the increase in recruitment of both species (Wieland, 2005a; Sünksen et al., MS 2006). In addition, the introduction of sorting grids in the shrimp fishery in 2000 has likely contributed to a reduction in bycatch mortality of juvenile Greenland halibut (Sünksen et al., MS 2006).

So far, no correlation between the changes in the indices of total survey biomass of Northern shrimp and the stock estimates for Greenland halibut were detected. However, the index of survey biomass of Northern shrimp comprises mainly 3-6 year old individuals whereas as the contribution of the recruits in terms of biomass is generally small because full catchability to the survey trawl is not achieved at that age (Wieland and Bergstöm, MS 2006). An impact of predation by Greenland halibut on Northern shrimp recruitment would therefore result in a change of the index of total survey biomass with a delay and a decline of the fishable stock of Northern shrimp will first become more prominent in the coming years (NAFO, MS 2006).

Increasing predation by Greenland halibut might have counterbalanced or even overruled the positive effect of the moderate increase in temperature on the survival of the pre-recruit stages of Northern shrimp in the most recent years, i.e. since 2000 when the recruit per spawner biomass index of Northern shrimp began to decline. It should, however, be noted here that the available time series is rather short and that other potentially important processes such as variations in larval transport towards suitable nursery areas (Ribergard et al., 2004), effects of changes in seasonal sea ice coverage (Ramseier et al., 2000) as well as the timing and the level of phytoplankton and zooplankton production (Fuentes-Yaco et $a l ., 2007)$ have not been included in the analysis due to insufficient information. Hence, the impact of Greenland halibut on Northern shrimp recruitment to the fishery warrants future studies and should so far be interpreted with some caution.

\section{Acknowledgements}

Jörg Appel (Institute for Sea Fisheries Hamburg) provided the geo-referenced data for Atlantic cod and bottom temperatures from the German groundfish survey, and we would like to thank him and his colleagues Manfred Stein and Hans-Joachim Rätz involved in the German groundfish survey for their cooperation. We also wish to acknowledge Steve Cadrin his critical review of an earlier version of the manuscript and Nicolas Bez for his comments related to the section on spatial distribution. 


\section{References}

BERGSTRÖM, B. I. 2000. The biology of Pandalus. Adv. Mar. Biol., 38: 55-245.

BERENBOIM, B. I., A. V. DOLGOV, V. A. KORZHEV, and N. A. YARAGINA. 2000. The impact of cod on the dynamics of Barents Sea shrimp (Pandalus borealis) as determined by multispecies models. J. Northw. Atl. Fish. Sci., 27: 69-75.

BEZ, N., and J. RIVOIRARD. 2000. Indices of collocation between populations. In: Report of a workshop on the use of the Continuous Underway Fish Egg Sampler (CUFES) for mapping spawning habitats of pelagic fish. D. M. Checkley, L. R. Hunter, L. Motos, and C. D. van der Lingen (eds.). GLOBEC Report, 14: 48-52.

BUCH, E., S. A. HORSTED, and H. HOVGÅRD. 1994. Fluctuations in the occurrence of cod in Greenland waters and their possible causes. ICES Mar. Sci. Symp., 198: $158-174$.

FRANK, K. T., B. PETRIE, N. L. SHACKELL, and J. S. CHOI. 2006. Reconciling differences in trophic control in mid-latitude marine ecosystems. Ecology Letters, 9: 1096-1105. doi:10.1111/j.1461-0248.2006.00961.x.

FUENTES-YACO, C., P. KOELLER, S. SATHYENDRANATH, and T. PLATT. 2007. Shrimp (Pandalus borealis) growth and timing of the spring phytoplankton bloom on the Newfoundland-Labrador shelf. Fish. Oceanogr., 16: 116-129. doi:10.1111/j.1365-2419.2006.00402.x

GRUNWALD, E. M. 1998. Nahrungsökologische Untersuchungen an Fischbeständen im Seegebiet vor Westgrönland. PhD Thesis, University of Kiel (Germany), $208 \mathrm{p}$.

HENDRICKSON, L., and A. VÁZQUEZ. 2005. Density-dependent changes in the spatial distributions of Atlantic cod (Gadus morhua), American plaice (Hippoglossoides platessoides) and Greenland halibut (Reinhardtius hippoglossoides) on the Flemish Cap during 1988-2002. J. Northw. Atl. Fish. Sci., 37: 53-72. doi:10.2960/J.v37. $\mathrm{m} 566$

HORSTED, S. A. MS 1978. The life cycle of shrimp, Pandalus borealis $\mathrm{Kr}$., in Greenland waters in relation to the potential yield. ICNAF Selected Papers, 4: 51-60.

HVINGEL, C., and M. C. S. KINGSLEY. 2006. A framework to model shrimp (Pandalus borealis) stock dynamics and to quantify the risk associated with alternative management options, using Bayesian methods. ICES J. Mar. Sci., 63: 68-82. doi:10.1016/j.icesjms.2005.09.002

ICES. MS 2006. Report of the North-Western Working Group. ICES CM Doc. 2006/ACFM:26, 612 p.

JØRGENSEN, O. A. 1997. Movement patterns of Greenland halibut, Reinhardtius hippoglossoides, at West Greenland, as inferred from trawl survey distribution and size data. $J$. Northw. Atl. Fish. Sci., 21: 23-37.

KINGSLEY, M. C. S. MS 2006. The fishery for Northern shrimp (Pandalus borealis) off West Greenland, 19702006. NAFO SCR Doc., No. 61, Serial No. N5309, 29 p.

LILLY, G., D. G. PARSONS, and P. J. VEITCH. 1998. Spatial structure of Northern shrimp (Pandalus borealis) off Labrador and eastern Newfoundland (Northwest Atlantic). In: G. S. Jamieson, and A. Campbell (eds.). Proceedings of the North Pacific Symposium on Invertebrate Stock Assessment and Management. Can. Spec. Publ. Fish. Aquat. Sci., 125: 265-271.

LILlY, G., D. G. PARSONS, and D. W. KULKA. 2000. Was the increase in shrimp biomass on the Northeast Newfoundland shelf a consequence of a release in predation pressure from cod? J. Northw. Atl. Fish. Sci., 27: 45-61.

MacDONALD, P. D. M., and T. J. PITCHER. 1979. Agegroups from size-frequency data: A versatile and efficient method of analysing distribution mixtures. J. Fish. Res. Bd. Can., 36: 987-1001.

MacDONALD, P. D. M., and P. E. J. GREEN. 1988. User's guide to program MIX: an interactive program for fitting mixtures of distributions. Release 2.3, January 1988. Ichthus Data Systems, Hamilton, Ontario, 60 p.

NAFO. MS 2006. Report of the NAFO/ICES Pandalus assessment group. NAFO SCS Doc., No. 27, Serial No. N5336, $68 \mathrm{p}$.

ORR, D., and W. R. BOWERING. 1997. A multivariate analysis of food and feeding trends among Greenland halibut (Reinhardtius hippoglossoides) sampled in Davis Strait, during 1986. ICES J. Mar. Sci., 54: 819-829. doi:10.1006/ jmsc.1996.0198

PARSONS, D. G. 2005a. Predators of Northern shrimp, Pandalus borealis (Pandalidae), throughout the North Atlantic. Mar. Biol. Res., 1: 48-58.

2005b. Interactions between Northern shrimp, Pandalus borealis (Pandalidae), and its key predators within the eastern Newfoundland and Labrador marine ecosystem. Mar. Biol. Res., 1: 59-67.

PEDERSEN, S. A., and F. RIGET. 1993. Feeding habits of redfish (Sebastes spp.) and Greenland halibut (Reinhardtius hippoglossoides) in West Greenland waters. ICES J. Mar. Sci., 50: 445-459. doi:10.1006/jmsc.1993.1048

PEDERSEN, S. A., and E. L. B. SMIDT. 2000. Zooplankton distribution and abundance in West Greenland waters, 1950-1984. J. Northw. Atl. Fish. Sci., 26: 45-102.

PEDERSEN, S. A., and J. RICE. 2002. Dynamics of fish larvae, zooplankton, and hydrographical characteristics in the West Greenland Large marine Ecosystem, 19501984. In: Large Marine Ecosystems of the North Atlantic: Changing States and Sustainability. K. Sherman and H. R. Skjoldal (eds.). Elsevier, Amsterdam, The Netherlands, p. 151-193.

PYPER, B. J., and R. M. PETERMAN. 1998. Comparison of methods to account for autocorrelation in correlation analysis of fish data. Can. J. Fish. Aquat. Sci., 55: 21272140. doi:10.1139/cjfas-55-9-2127

RAMSEIER, R., C. GARRITY, D. G. PARSONS, and P. KOELLER. 2000. Influence of particulate organic carbon sedimentation within the seasonal sea-ice regime on the catch distribution of Northern shrimp (Pandalus borealis). J. Northw. Atl. Fish. Sci., 27: 35-44.

RIBERGAARD, M. H. MS 2006. Oceanographic observations off West Greenland 2005. NAFO SCR Doc., No. 1, Serial No. N5210, 36 p.

RIBERGAARD, M. H., S. A. PEDERSEN, B. ÅDLANDSVIK, and N. KLIEM. 2004. Modelling the ocean circulation on the West Greenland shelf with special emphasis 
on Northern shrimp recruitment. Cont. Shelf Res., 24: 1505-1519. doi:10.1016/j.csr.2004.05.011

ROSING, M., and K. WIELAND. MS 2005. Preliminary results from shrimp trawl calibration experiments off West Greenland $(2004,2005)$ with notes on encountered experiment design / analyses problems. NAFO SCR Doc., No. 92, Serial No. N5197, 6 p.

SHUMWAY, S. E., H. C. PERKINS, D. F. SCHICK, and A. P. STICKNEY. 1985. Synopsis of biological data on the pink shrimp, Pandalus borealis (Krøyer, 1838). NOAA Technical Report NMFS30 / FAO Fisheries Synopsis, No. $144,57 \mathrm{p}$.

SKÚLADÓTTIR, U., J. PÁLSSON, G. S. BRAGASON, and S. BRYNJÓLFSSON. MS 1991. The variation in size and age at change of sex, maximum length and length of the ovigerous periods of the shrimp, Pandalus borealis, at different temperatures in Icelandic waters. ICES CM Doc. 1991/K:5, 15 p.

STEFÁNSSON, G., U. SKÚLADÓTTIR, and B. Æ. STEINARSSON. 1998. Aspects of the ecology of a boreal system. ICES J. Mar. Sci., 55: 859-862.

SÜNKSEN, K., M. STORR-PAULSEN, and O. A. JØRGENSEN. MS 2006. Biomass and abundance of demersal fish stocks off West Greenland estimated from the Greenland shrimp survey, 1988-2005. NAFO SCR Doc., No. 28, Serial No. N5247, $30 \mathrm{p}$.

WIELAND, K. MS 2004. Recruitment of Northern shrimp
(Pandalus borealis) off West Greenland in relation to spawning stock size and environmental variation, 19932004. NAFO SCR Doc., No. 74, Serial No. N5044, 9 p.

2005a. Changes in recruitment, growth and stock size of northern shrimp (Pandalus borealis) at West Greenland: temperature and density-dependent effects at released predation pressure. ICES J. Mar. Sci., 62: 14541462. doi:10.1016/j.icesjms.2005.02.012

MS 2005b. Conversion of Northern shrimp (Pandalus borealis) biomass, recruitment and mean size from previous years (1988-2004) to the new standard trawl used in the Greenland Bottom Trawl Survey at West Greenland in 2005. NAFO SCR Doc., No. 75, Serial No. N5180, 6 p.

WIELAND, K., and B. BERGSTRÖM. MS 2006. Results of the Greenland Bottom Trawl Survey for Northern Shrimp (Pandalus borealis) off West Greenland (NAFO Subarea 1 and Division 0A), 1988-2006. NAFO SCR Doc., No. 58, Serial No. N5306, 35 p.

WIELAND, K., and M. STORR-PAULSEN. MS 2004. A comparison of different time series of Atlantic cod (Gadus morhua) biomass at West Greenland and their potential use for the assessment of Northern shrimp (Pandalus borealis) in NAFO Subarea 1. NAFO SCR Doc., No. 71, Serial No. N5041, 9 p.

WORM, B., and R. A. MYERS. 2003. Meta-analysis of codshrimp interactions reveals top-down control in oceanic food webs. Ecology, 84: 162-173. 